JGG 2020;68:53-56

doi: 10.36150/2499-6564-325

\title{
Infra-hissian Wenckebach phenomenon. A case report, with some reflection about slow conduction
}

\author{
Marcello Costantini ${ }^{1,3}$, Lorenzo Costantini ${ }^{2}$, Michele Maffia ${ }^{3}$ \\ ${ }^{1}$ Scuola di Specialità in Cardiologia. Università degli Studi di Foggia, Italy; ${ }^{2}$ Struttura Complessa \\ Cardiologia-Ospedale Santa Caterina Novella. ASL Lecce, Galatina-Lecce, Italy; ${ }^{3}$ Laboratorio di \\ ricerca DREAM-Università del Salento/ASL Lecce, Italy
}

We describe a case of Wenckebach periodicity in the distal conduction system. Our observation strengthens the concept that Wenckebach type block in surface ECG may reflect block in infra-hissian tissues, especially if there is a wide QRS complex in the conducted beats.

Key words: Wenckebach, slow conduction, AV block

Received: April 12, 2019

Accepted: December 9, 2019

\section{Correspondence}

Marcello Costantini

Struttura Complessa Cardiologia-Ospedale Santa Caterina Novella. ASL Lecce, Galatina, via Montegrappa 156, Galatina-Lecce, Italy E-mail: marcellocostantini9@gmail.com

\section{Conflict of interest}

The Authors declare no conflict of interest

How to cite this article: Costantini M, Costantini L, Maffia M. Infra-hissian Wenckebach phenomenon. A case report, with some reflection about slow conduction. Journal of Gerontology and Geriatrics 2020;68:53-6. https://doi. org/10.36150/2499-6564-325

C Copyright by Società Italiana di Gerontologia e Geriatria (SIGG)

\section{(c) (i) $(9)$}

\section{OPEN ACCESS}

This is an open access article distributed in accordance with the CC-BY-NC-ND (Creative Commons Attribution-NonCommercial-NoDerivatives 4.0 International) license. The article can be used by giving appropriate credit and mentioning the license, but only for non-commercial purposes and only in the original version. For further information: https://creativecommons.org/licenses/by-nc-nd/4.0/deed.en
The Wenckebach phenomenon, or Mobitz type $1 \mathrm{AV}$ block, is one of the most common eponymus used in medicine. The diagnostic criteria, unchanged since Wenckebach described them ${ }^{1}$, are progressive prolongation of the PR interval on surface ECG and shortening of the RR interval until a $P$ wave is blocked. Tipically, the RR interval encompassing the nonconconducted $\mathrm{P}$ wave is less than the sum of two PP interval. During a classical Wenckebach phenomenon, the increment of conduction time is greatest in the second beat of periodicity, and the increment in conduction delay decrease over the subsequent beats ${ }^{2}$. Although is a popular opinion that Wenckebach periodicity reflects $\mathrm{AV}$ nodal block, such electrocardiographic phenomenon is not in itself diagnostic of an AV node conduction disturbance. We report here a case in which a manifest pattern of Wenckebach periodicity was observed in an elderly woman, with electrophysiological evidence of infra-hissian level of block.

\section{CASE REPORT}

A 80-years old woman with hypertension, mild cronic renal failure, in cronical treatment with digitalis, nifedipine, ramipril, furosemide, was admitted for a recent history (few days) of sudden fainting (without syncope), lasting a few second, often with dyspnea at the same time. On admission, she was asymptomatic; physical examination was consistent with aortic valve pathology, and revealed occasionally missing pulse. The blood pressure was $180 / 70 \mathrm{mmHg}$. There was not evidence of heart failure. Echocardiogram showed calcific aortic valve disease, with mild stenosis and moderate regurgitation; an hypertrophic, not dilated, left ventricle was evident, with good systolic function. Laboratory data showed a mild-moderate renal failure, with $2.2 \mathrm{mg} / \mathrm{dl}$ of creatininemie level. A good reason for digitalis therapy was totally missing, howevere the serum level of the drug was inside acceptable range (1.02 ng/ml).

The electrocardiogram (ECG) showed presence of sinusal rhythm at frequence of $78 \mathrm{~b} / \mathrm{min}$, with intraventricular conduction characterized by 
right bundle branch block. In addiction, the PR interval was prolonged, with type 1 second degree AV block (Wenckebach phenomenon), and 3:2 and 4:3 AV ratios (Fig. 1). The patient was quickly subjected to electrophysiological studies, in order to define the level of block.

The endocavitary electrical activity derived at His level during Wenckebach periodicity showed normal $\mathrm{AH}$ interval, while HV interval, within normal range at the start of sequence, manifest a progressive lengthened, until $\mathrm{H}$ wave is not followed by a $\mathrm{V}$ wave (Fig. 2). Thus, the block level was found below the His bundle. Furthermore, during electrophysiological study, the intraventricular conduction of the first $P$ wave that follow the blocked $P$ wave, showed always (togheter with right bundle branck bloch) a typical phase 4 posterior left hemiblock, a further sign that a critical disease of the distal conduction was present (Fig. 3). The patient was advised to undergo permanent pace maker implantation, and the procedure was soon performed without any problem.

\section{DISCUSSION}

Syncope or pre-syncope, a relevant clinical problem especially in the geriatric population, can be defined as "neuromediated", "cardiac", "drug-induced", "multifactorial" or "unexplained" 3 . Although neuromediated syncope is the most frequent, cardiac syncope has a far worse prognosis, accompanied by high mortality ${ }^{3}$. In this context, the bradyarrhythmic mechanism, linked to sinus node disease or distal conduction disorders, occupies a preponderant role. It is important to recognize in time a sick sinus syndrome or a widespread distal disease of the conduction system in order to implement the related therapeutic measures before serious adverse events. Simple concepts of the physiology and a sufficient knowledge of the electrocardiogram can help clinicians even in clinicelectrocardiographic contexts that are not easy to interpret. Conduction velocity in cardiac tissues is determined primarily by membrane excitability (ie, the magnitude and kinetics of depolarizing currents) and by the degree of intercellular gap junctional coupling ${ }^{4-6}$. In the AV node, both reduced excitability (conduction is based predominantly

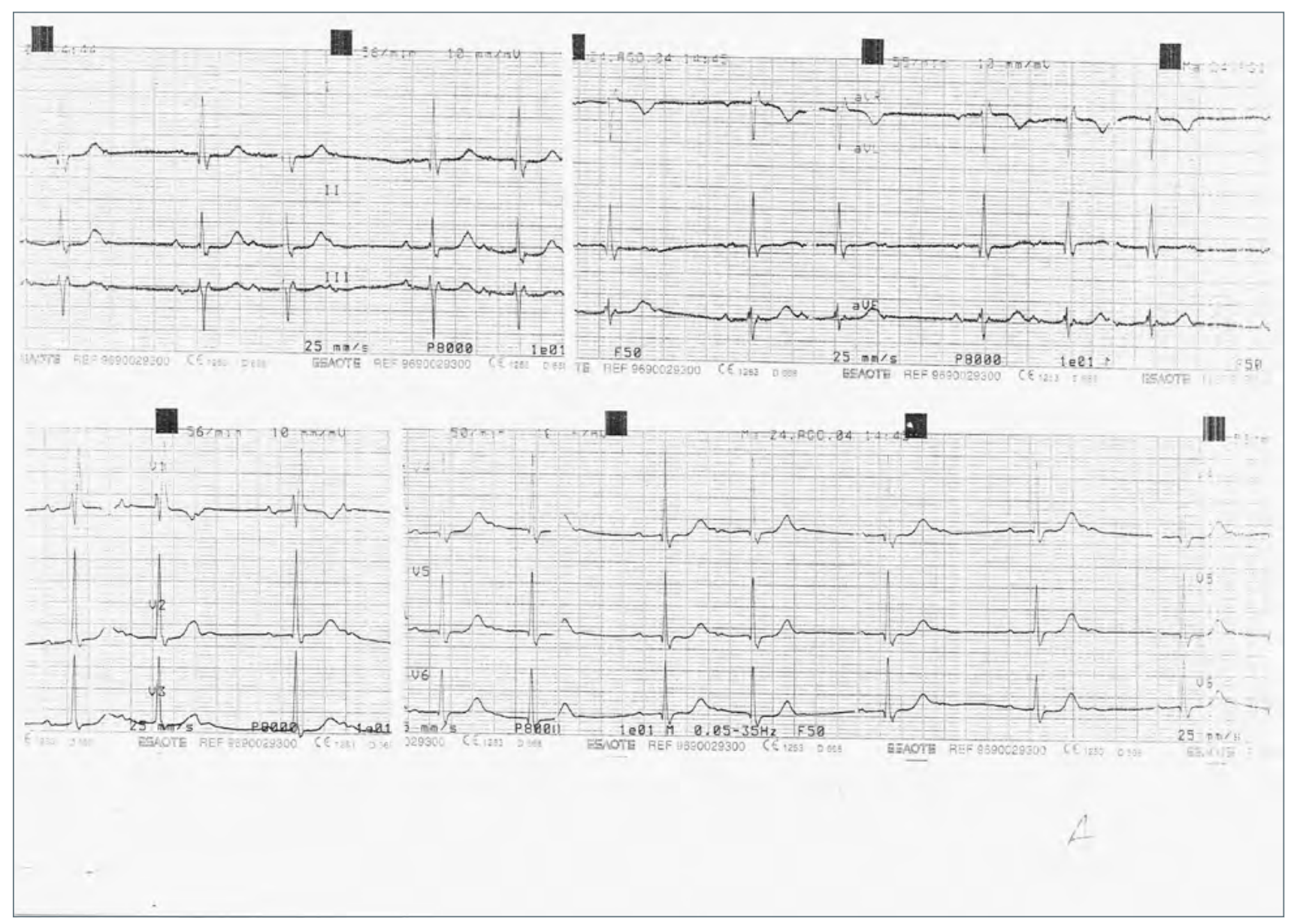

Figure 1. ECG at the admission (see text). 


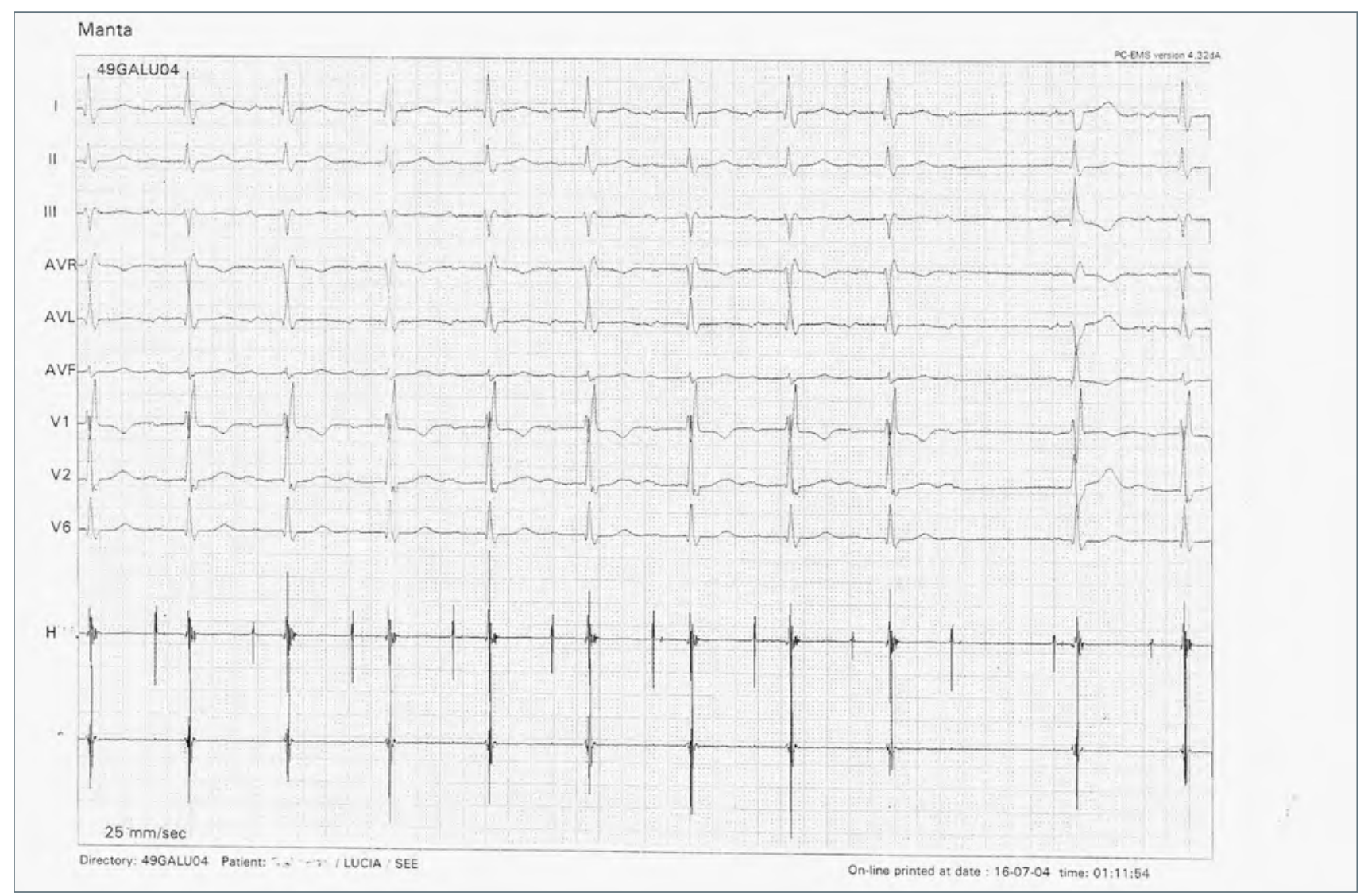

Figure 2. Second degree AV block during endocavitary study at $25 \mathrm{~mm} / \mathrm{sec}$ paper speed. The registration of His bundle potential disclose the distal site of block. Notice the phase 4 posterior hemiblock after the resumption of conduction.

on the L-type Ca2-channels) and reduced gap junctional coupling are the major mechanisms of very slow conduction ${ }^{67}$. Furthermore, it is well estabilited that in the AV node nonuniform anisotropy contributes to discontinuous, slow conduction in the direction transverse to myocardial fibers ${ }^{8}$. Finally, slow conduction and/or block is also influenced by the presence of structural inhomogeneities within AV node tissue. Such inhomogeneity can create an electrical source-to-load mismatch ${ }^{9}$, a misbalance between the current provided by a smaller mass of tissue (source) and the current necessary to bring to threshold a larger mass of tissue downstream (load).

Although in normal state these mechanism of slow/ decremental conduction are almost restricted in AV nodal and surroundings tissues, under a lot of functional and structural derangement they may act also in the common myocardial working fibers and/or in distal conduction pathways creating the condictions for slow conduction, block and reentry ${ }^{10-12}$.

Since a slow/decremental conduction are usually tipical of $A \bigvee$ node, a periodic AV conduction disturbance where a $P$ block was heralded by progressive increment of PR tract, is usally referred as a manifestation of AV nodal block. This peculiar behaviour was firtst described by Wenckebach long before the invention of the ECG ${ }^{1}$. He described it as a form of conduction disturbance characterized by a progressive lengthening of the interval between the "a" and the "c"waves of the jugular pulse, terminating in a dropped "c" wave. But Wenckebach periodicity is not sinonimous of AV nodal block! Only if there is a narrow QRS complex in the conducted beats the likely of nodal block is very hight, because a type I block in the His bundle is very rare. However, in a type I second-degree AV block with a wide QRS (> $120 \mathrm{msec}$ ), the distal site of block is not rare ${ }^{2}$. Often, this conduction disturbance indicates diffuse disease of the His-purkinje system, with a poor prognosis that is believed to be the same as for type 2 second-degree AV block (in most patients, even asynptomatic, a permanent pace maker should be considered). The diagnosis of type 1 infrahisian block require usually invasive His bundle recording, but some aspects on surface ECG (for istance intermittent phase 4 left posterior hemiblock, as in our case) may render the electrophysiological investigation actually redundant.

In conclusion, our case strengthens the concept that Wenckebach type block in surface ECG may reflect 


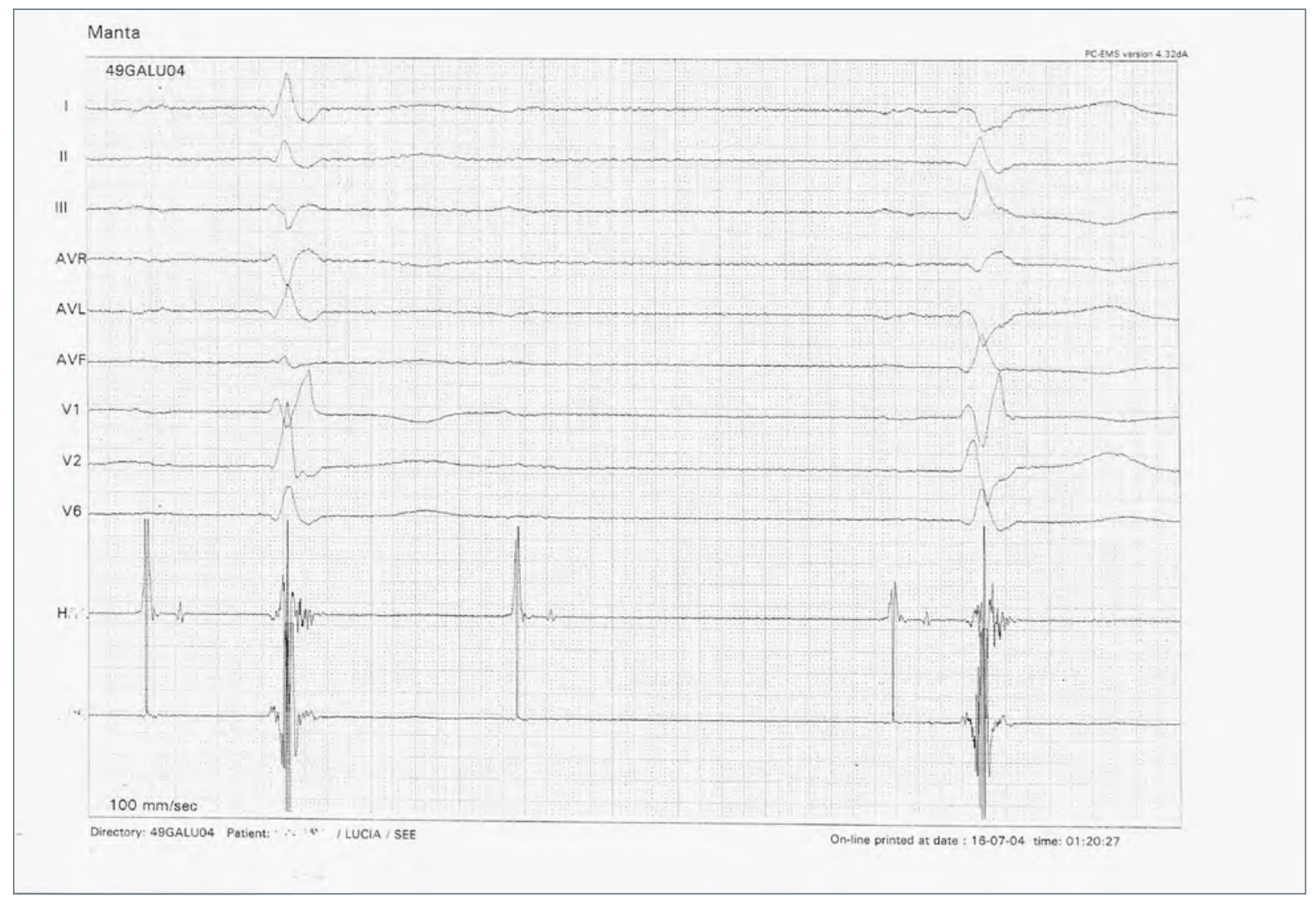

Figure 3. The same findings of the Figure 2, at $100 \mathrm{~mm} / \mathrm{sec}$ paper speed.

block in infra-hissian tissue, especially if there is a wide QRS complex in the conducted beats.

\section{References}

1 Wenckebach KF. Zur Analyse Des Unrezelmasigen Pulse. II. Uber Den regelmasig intermitterenden Pulse. Zscher Klin Med 1899;37:475.

2 Fisch C. Atrioventricular conduction. In: Electrocardiography of arrhythmias. Philadelphia: Lea \& Febiger 1990, pp. 347-85.

3 Ungar A, Galizia G, Morrione A, et al. Two-year morbidity and mortality in elderly patients with syncope. Age Ageing 2011;0:1-6.

4 Costantini M. Aritmie a colpo d'occhio. Pavia: Materia Medica 2019, pp. 57-9.

5 Joyner RW. Effects of the discrete pattern of electrical coupling on propagation through an electrical syncytium. Circ Res 1982;50:192-200. https://doi.org/10.1161/01.res.50.2.192

6 Shaw RM, Rudy Y. Ionic mechanisms of propagation in cardiac tissue: roles of the sodium and L-type calcium currents during reduced excitability and decreased gap junction coupling. Circ Res 1997;81:727-41. https://doi.org/10.1161/01. res.81.5.727
7 Rohr S, Kucera JP, Kléber AG. Slow conduction in cardiac tissue, I: effects of a reduction of excitability versus a reduction of electrical coupling on microconduction. Circ Res 1998;83:781-94. https://doi/org/10.1161/01.res.83.8.781

8 Hocini M, Loh P, HoSY, et al. Anisotropic conduction in the Triangle of Koch in mammalian hearts: electrophysiologic and anatomic correlations. JACC 1988;31:629-36. https://doi. org/10.1016/s0735-1097(97)00519-6

9 Kucera JP, Rudy Y. Mechanistic insights into very slow conduction in branching cardiac tissue. Circ Res 2001;89:789906. https://doi.org/10.1161/hh2101.098442

10 Rohr S, Kucera JP, Kleber AG. Slow conduction in cardiac tissue. Circ Res 1988;83:795-805. https://doi.org/10.1161/01. res.83.8.781

11 Kléber AG, Janse MJ, Wilms-Schopmann FJG, et al. Changes in conduction velocity during acute ischemia in ventricular myocardium of the isolated porcine heart. Circ Res 1986;73:189-98. https://doi.org/10.1161/01.cir.73.1.189

12 Spach MS, Dolber PC. Relating extracellular potentials and their derivatives to anisotropic propagation at a microscopic level in human cardiac muscle: evidence for electrical uncoupling of side-to-side fiber connections with increasing age. Circ Res 1986;58:356-71. https://doi.org/10.1161/01. res.58.3.356 